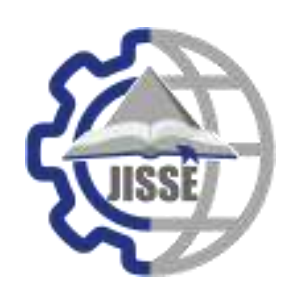

\begin{tabular}{c}
\hline \hline JISSE \\
ISSN: 2636-4425 \\
\hline
\end{tabular}

\title{
Voltage Stability Enhancement and Power Oscillation Damping of a Grid-Connected Wind Power Plant based on Dynamic Optimized GA-PI Controller
}

\author{
Ahmed A. Zaki Diab ${ }^{1, *}$, Hassan Ali Sayed ${ }^{2}$, G. A. Elsaady ${ }^{3}$ and Abohashema M. ElSayed ${ }^{4}$ \\ 1,2,4 Dept. of Electrical Engineering, Faculty of Engineering, Minia University, Minia 61111, Egypt \\ ${ }^{\text {I} D e p t . ~ o f ~ E l e c t r i c a l ~ E n g i n e e r i n g, ~ K y u s h u ~ U n i v e r s i t y, ~ F u k u o k a ~ 819-0395, ~ J a p a n ~}$ \\ ${ }^{3}$ Dept. of Electrical Power and Machine, Faculty of Engineering, Assiut University, Assiut, Egypt
}

\section{A R T I C LE IN F O \\ Article history: \\ Received:30-09-2019 \\ Accepted:29-11-2019 \\ Online:05-12-2019}

Keywords:

Wind Energy System

STATCOM

On-Line Tuning; Dynamical

Optimization

GA-PI Controller

\begin{abstract}
A B S T R A C T
Nowadays, the integration of wind energy plants with electrical power systems is increasing rapidly. Moreover, the stability of the power system is affected by the integration of wind energy plants. In this paper, a novel controller has been designed for improving the transient stability of the gridconnected wind generators using STATCOM based on dynamic online optimized GA-PI controller in order to enhance the damping of system oscillations. The STATCOM control scheme for the grid-connected wind energy generation system for power quality improvement is simulated using MATLAB/SIMULINK in power system block set. The results show the application of the STATCOM based on the proposed intelligent controller improve the overall performance of the control system such as the reduction of the voltage fluctuation. In order to validate the proposed scheme, the simulation results have been compared with this without STATCOM. The results show that the proposed controller can accelerate the dynamic response of control system, strengthen the robustness and smoothly operation with respect to the voltage and power response as well as precisely. This paper designates the distinguished performance of the proposed dynamic optimized controller for the control of the active and reactive power of the grid-connected wind power plants.
\end{abstract}

\section{Introduction}

Renewable energy has been considered an essential significance due to scarcity of fossil fuel. Furthermore, increasing electrical energy demand and growing environmental concerns. Integration of the wind power plants with the power systems causes significant effects in the performance of the grid. The transient performance is a critical problem which needs more research. The application of the flexible AC transmission systems (FACTS) improves the power quality and dynamic transient performance of the overall system. Moreover, FACTS compensators are applied for solving the transit problems in case of the nonlinear loads and abnormal conditions. STATCOM is one of the FACTS compensators which can control the reactive power of the system with WES, [1-3].

\footnotetext{
*Ahmed A. Zaki Diab, Faculty of Engineering, Minia University, Minia 61111, Egypt, +20102177792 \& a.diab@mu.edu.eg
}

Traditional control algorithms have been presented for FACTS compensators such as PI regulators [4]. However, the fixed parameters controllers have many limitations with respect to the different operating conditions [1, 3, 5-7]. However, the system of the power plant integrated with different types of renewable energy resources is a multivariable and strong coupling nonlinear system, the application of the traditional fixed PID controller with such systems cause the system to have insufficiencies. Such control systems with conventional PID controllers are sensitive to the plant uncertainties and unexpected disturbance. So, the overall performance of control system can be seriously degraded under parameter variations. furthermore, the gains of the traditional fixed parameters PID controller need to be chosen with exact precision, [4, 8].

In recent years, many researchers introduced their control approaches for improving the overall performance of the Wind 
Energy System (WES) [8]. SVC and STATCOM have been presented based on the conventional controller for enhancing the dynamic performance of the integrated WES with the Utility grid [5, 9-19]. Neuro-fuzzy has been applied for controlling STATCOM and SSSC to ensure system stability under abnormal conditions [11]. Another research has been presented for enhancing the power quality and the system performance with WES in[18]. The impact of STATCOM compensators for enhancing the dynamic stability during transit operation of WES has been presented in [2]. These modern intelligence algorithmsbased controllers have been introduced to control of Wind Energy Systems and other plants and always showed better performance than the conventional PID controller. Authors in Ref.[20] studied a fuzzy neural network controller for damping power system oscillations. It was proven that bat fuzzy neural network controller has superior performance than the other controllers. Moreover, the high stability and reliability of conventional PID were combined with the strong adaptive ability and robustness of neural network. Authors in Ref. [9], presented an offline optimized PID controller based on particle swarm optimization (PSO). Safariet al. introduced an offline design of STATCOM parameters based on a Honey Bee Mating Optimization (HBMO) algorithm, also a comparison with Genetic Algorithm (GA) has been made to validate the HBMO algorithm, [21].

Although the controller PI that are off-line tuned by optimization techniques; is better than the PI controller that adjusted classically, the premature convergence and entrapment in local minima degrade the performance of the system. Moreover, the introduced optimal controller in the literature is offline tuning with respect to one operating point which also may cause poor performance of the control systems. To overcome the disadvantages of PI controllers obtained from the offline optimization algorithm, an advanced dynamic online tuning based on GA optimization algorithms is presented in this paper.

This paper presents a novel dynamical optimized PI-GA controller based STATCOM for improving the transient stability of the WES. The case study is the three-machine nine-bus western system coordinate council (WSCC) power system. The wind power plant has been integrated with the power system. The proposed dynamic GA is applied for on-line tuning the parameters of the PI controllers to act with the different operating conditions. MATLAB/SIMULINK has been used to validate the control system through simulation. The system has been tested under three-phase short circuit at different locations.

\section{Configuration of the System under Study}

Figure 1 shows the configuration of the system under study. A wind power plant has been installed at bus no. 3. The wind power plant is based on the DFIG. The wind power plant has three wind farms of 20 turbines of $1.5 \mathrm{MW}$. The STATCOM rated is 100 MVAR. The data of the overall system is illustrated in Table 1.

\section{Proposed Dynamical Optimized GA-PI controller}

In this section the proposed controller based on Genetic Algorithms has been presented.
Table 1: The parameters of wind turbine based DFIG

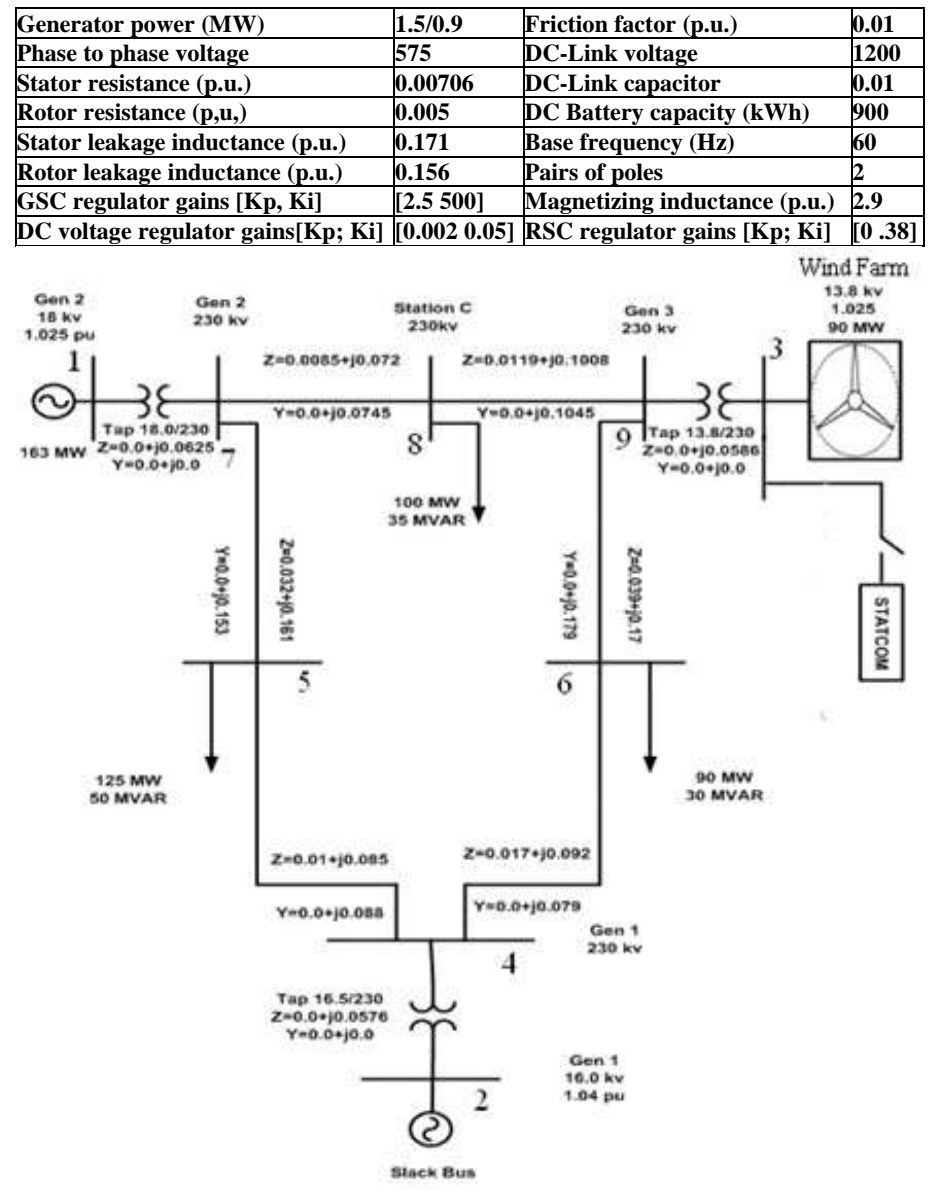

Figure 1: Studied power system configuration (60 Hz, 100 MVA Base)

\subsection{Genetic algorithm}

Genetic Algorithms (GA) is applied to control systems in many engineering fields. Moreover, the researchers in many published works prove that has an acceptable performance in various applications. The main steps of the GA execution may be summarized as the following [22, 23]; In general, the following step is executed in the course of applying GA:

1) Starting with the initial population; 2) calculating the fitness function (objective function); and 3) executing Genetic Algorithms actions (crossover, mutation). The pseudo-code of the GA can be written as follows:

- BEGIN /* genetic algorithm*/

- Generate initial population;

- Compute fitness of each individual;

- WHILE NOT finished DO LOOP BEGIN

- Select individuals from old generations for mating;

- Create offspring by applying recombination and/or mutation to the selected individuals;

- Compute fitness of the new individuals;

- Kill old individuals to make room for new chromosomes and insert offspring in the new generation; 
- IF Population has converged THEN finishes: = TRUE;

END

- END

Moreover, Figure 2 shows the flowchart of GA process.

\subsection{Optimized GA-PI controller}

The GA-PI controller has been shown in Figure 3 . The GA is used for on-line generating the parameters of the PI controllers to meet the required specification. ISE performance index has been used to depict the system performance as the objective function of the optimization algorithm of GA. ISE index can be expressed as:

$$
\text { ISE }=\int_{0}^{\infty} e^{2}(t) d t
$$

Therefore, the objective function of the ISE in the GA is to seek a tune of PI gains such that the feedback control system has minimum performance index.

\section{STATCOM based Dynamic Optimized GA-PI Controller}

STATCOM is a solid-state switching converter that feeds by capacitor or energy-storage device [2]. The output lagging or leading reactive current is regulated independent of the $\mathrm{AC}$ system voltage. Moreover, STATCOM involves of a voltage source converter which can generate 3-phase voltages. In this study, the VSC has been motivated via a dc storage capacitor. The configuration of STATCOM has been shown in Figure 4, [24].

STATCOM is applied for filtering harmonics and enhancing transient stability. Furthermore, it can transact with the voltage collapse. The transferred reactive power between the STATCOM device and the power system accomplished through controlling the magnitude of the voltage as, $[2,24]$.

$$
Q_{c}=\frac{V_{1}^{2}}{X_{t r}}-\frac{V_{1} V_{s}}{X_{t r}} \cos \left(\theta_{s}-\theta_{0}\right)=\frac{V_{1}^{2}-V_{1} V_{S}}{X_{t r}}
$$

Where, Qc is the reactive power exchange between STATCOM and UG, V1is UG voltage, Vs is STATCOM output terminal voltage, and Xtr is the Transformer leakage reactance.

Matlab/Simulink model of STATCOM based on the proposed dynamic optimized PI-GA has been shown in Figure 5. The error signal between the reference voltage and measured voltage is used to calculate the objective function which fed to the online GA. The output of the GA is used for online tuning of the parameters of the PI controller. The error signal is fed to the optimized PI-GA controller that provides the reactive reference current Iqref. The STATCOM reactive current Iq is compared with Iqref, and the output of the current regulator is the angle phase shift of the PWM inverter.

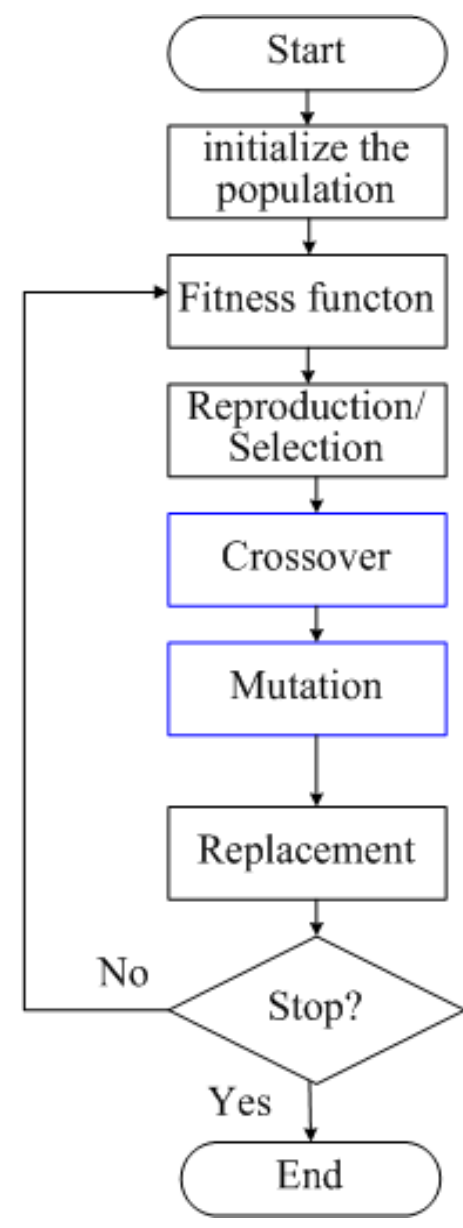

Figure 2: Flow Chart of GA Process

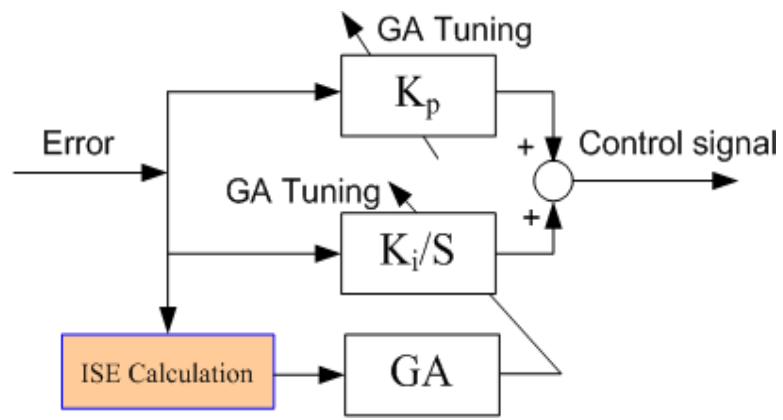

Figure 3: Optimized GA-PI controller

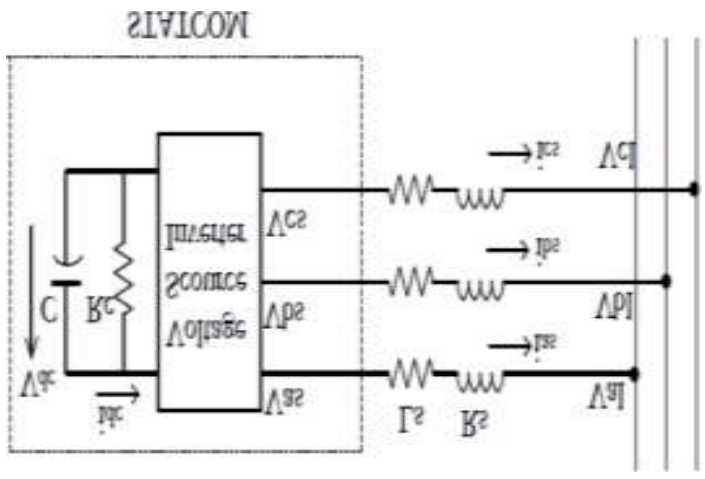

Figure 4: Schematic diagram of STATCOM 


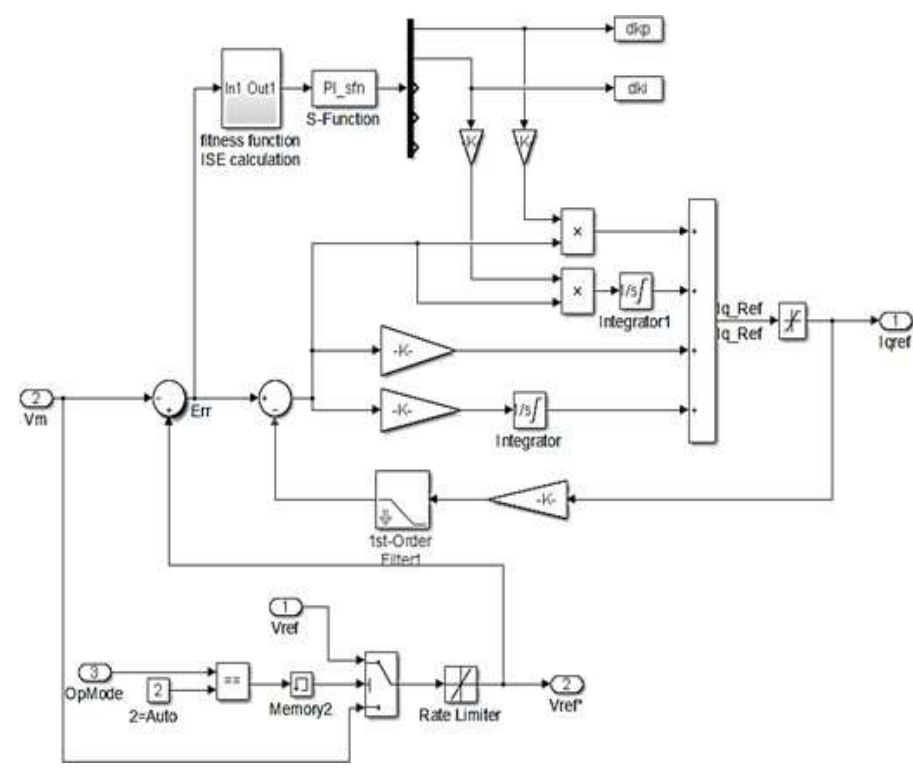

Figure 5: Matlab/Simulink model of STATCOM Based proposed dynamic optimized PI-GA

\section{Simulation Results}

The Simulink model of the WSCC power system has been shown in Figure 6. The system is combined with STATCOM using the dynamic optimized PI-GA controller. The system is evaluated through applying a 3-phase to ground short circuit fault. The stability performance of the system for different locations of the fault can be analyzed as the following:

\subsection{Case 1:.Fault located at WF Bus 3}

A three-phase fault is assumed to have occurred at wind farm (WF) Bus 3. The fault is assumed occurred at 4.0 second and cleared at 4.1 seconds. Figure 7 shows the dynamic time response of STATCOM reactive power and the DC voltage of the STATCOM based on the proposed optimized online PI-GA controller.

The dynamic performance of the generator 1 with/without STATCOM based on proposed dynamic optimized PI-GA controller has been shown in Figure 8. The results show that the system using STATCOM device based on the proposed dynamic optimized PI-GA controller is faster and has a good dynamic performance with respect to the steady state time and overshoot.

For more visualization of the system performance under the same condition of three-phase faults at WF Bus 3, the dynamic performance of generator 2 and the wind farm of bus 3 has been shown in Figures 9and 10, respectively. From results, the system using STATCOM based on optimized dynamic PI- GA device has a steady state time less than $0.1 \mathrm{sec}$. but the performance of the without Facts device has a time of 0.15 second to reach the steady state. Moreover, Figure 8 shows that the system with STATCOM based on optimized dynamic PI-GA has a good dynamic performance during the fault duration. The system with the proposed STATCOM has a steady state time of 0.07 second.

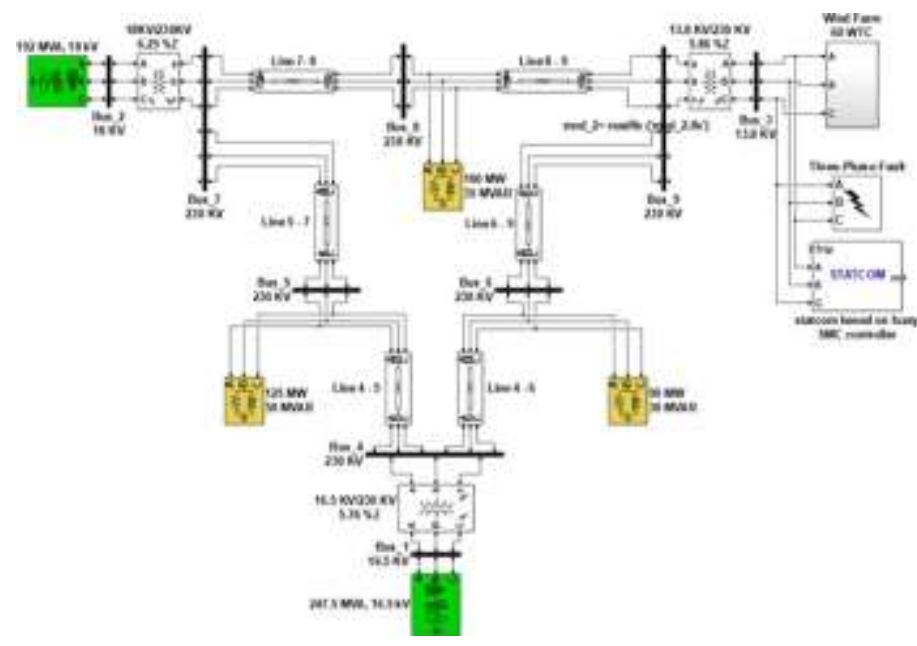

Figure 6: Simulink model of the overall studied system.
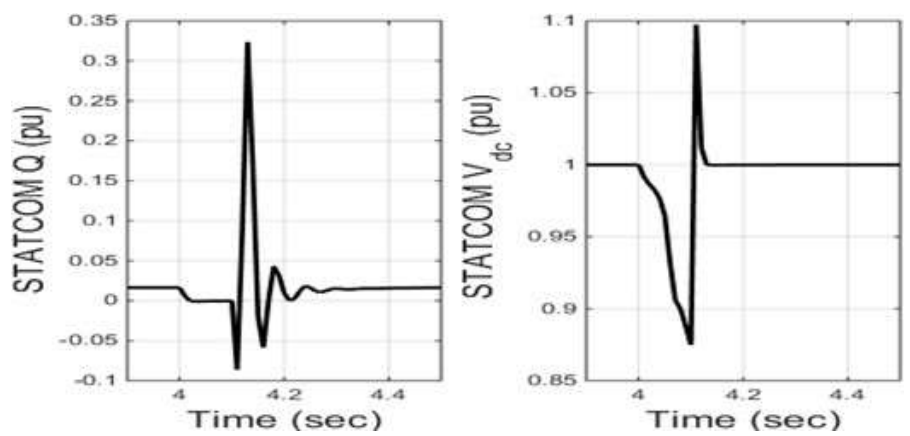

Figure 7: Dynamic time response of STATCOM reactive power and DC voltage based on optimized online PI-GA controller, Case 1.
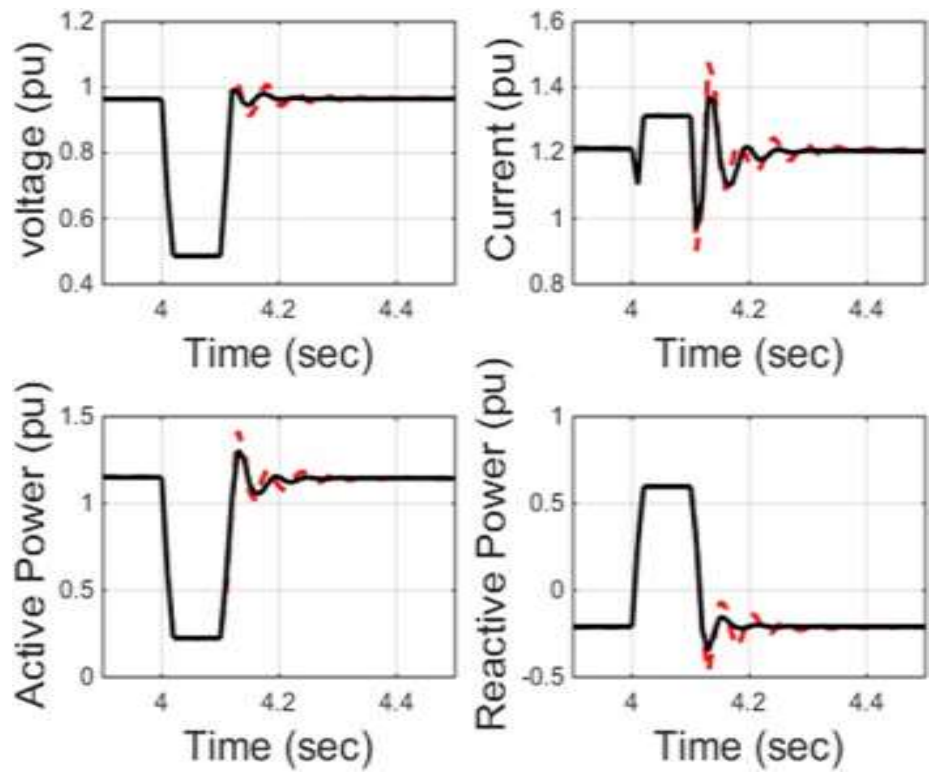

Figure 8: Dynamic performance of generator 1 with and without STATCOM, Case 1; (solid black line for with STATCOM and dashed red line for the case without STATCOM) 

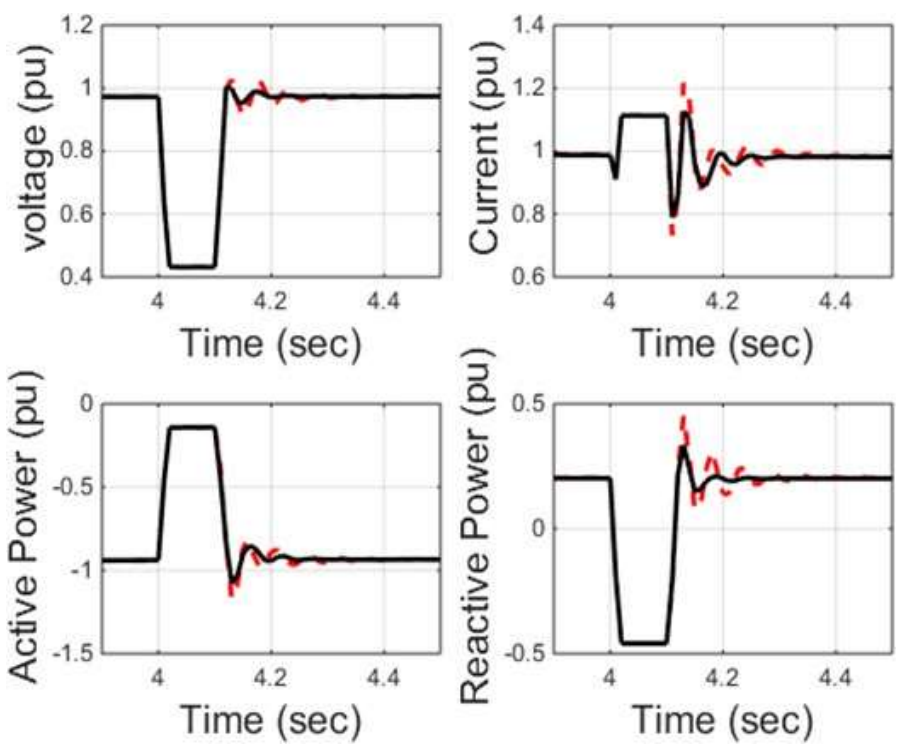

Figure 9: Dynamic response of Gen. 2, Case 1; (solid black line for with STATCOM and dashed red line for the case without STATCOM)

For more validating of the system performance with the STATCOM based proposed controller, Figure 11 shows the dynamic performance of the voltage at the reset of buses. Moreover, the figure shows the dynamic performance of the voltage at buses of $\mathrm{B} 6, \mathrm{~B} 7, \mathrm{~B} 8$ and $\mathrm{B} 9$ are stables and have a good dynamic performance. Furthermore, the system with STATCOM based optimized dynamic PI-GA has smaller settling time and overshoot.
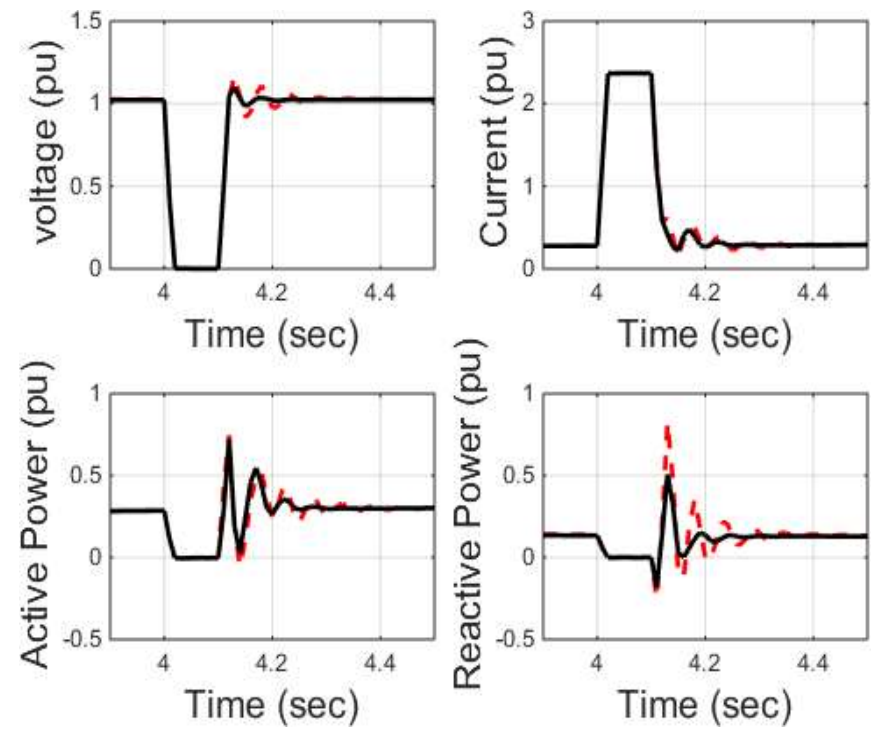

Figure 10: Dynamic response of wind farm, Case 1;(solid black line for with STATCOM and dashed red line for the case without STATCOM)

\subsection{Case2: Fault located at Bus 8}

Another case of study has been tested for more validation of the proposed controller based on the dynamic optimized PI-GA algorithm. A three-phase fault has been assumed to occur at bus 8 . The dynamic performance of the generator 1 under this case under study has been shown in Figure 12. Figure 12 shows that the system using STATCOM based on the proposed optimized dynamic PI-GA have a time of 0.07 second. But the system without STATCOM takes more time to reach stability.

Figures 13 and 14 show the performance of the system at generator 2 and WF. The results show the system with the STATCOM based on optimized dynamic PI-GA has better time response. Moreover, the dynamic performance of the voltage at the reset of busses has been shown in Figure 15. The results show that the dynamic performance of all system buses voltage enhanced by installing the STATCOM based on the proposed optimized dynamic PI-GA. The performance of the system with the STATCOM has a good settling time and an acceptable overshoot.
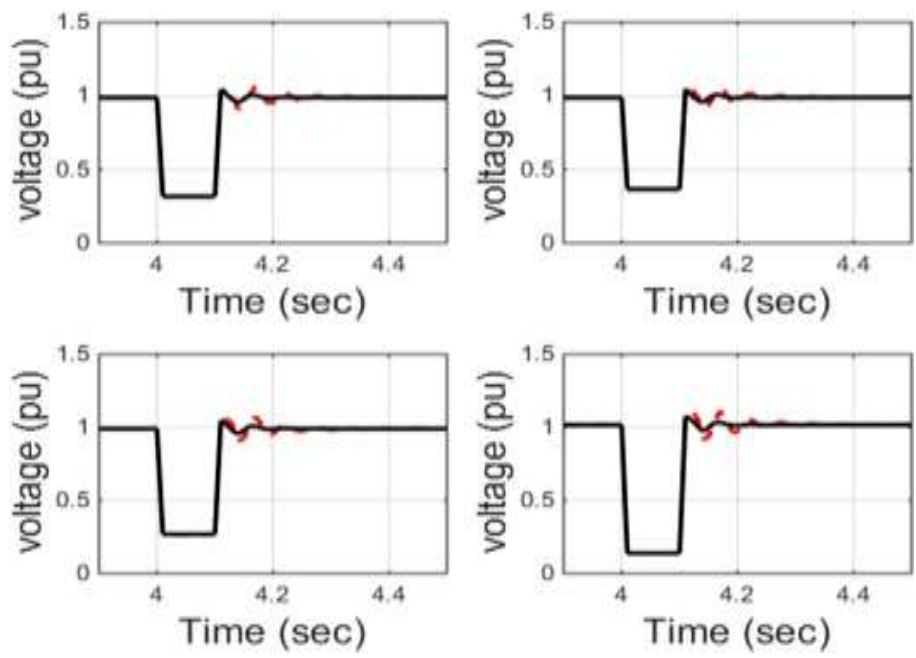

Figure 11: Dynamic performance of voltage at Buses B6, B7, B8 and B9, Case 1; (solid black line for with STATCOM and dashed red line for the case without STATCOM)
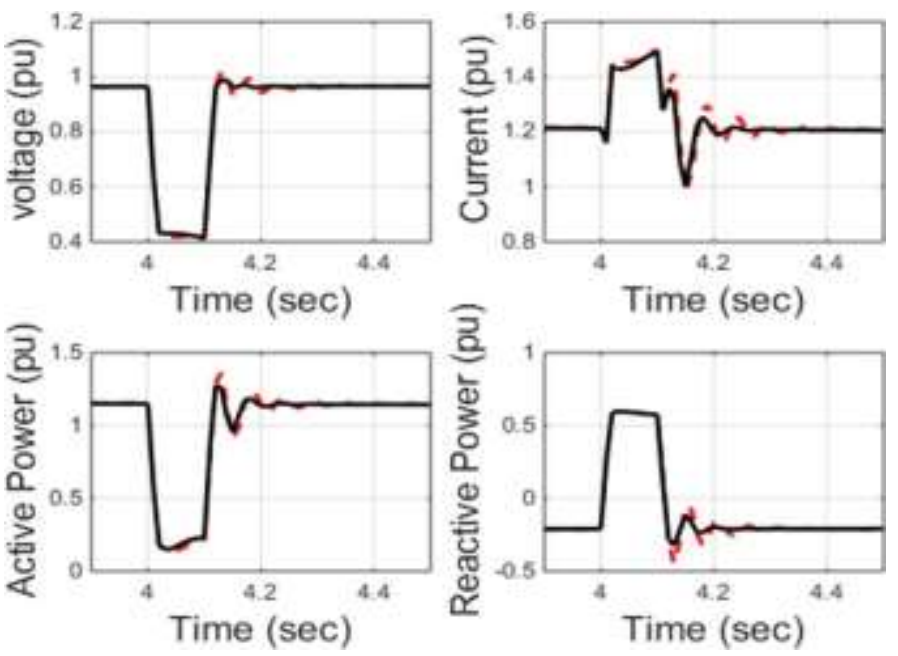

Figure 12: Dynamic performance of generator 1, Case 2; (solid black line for with STATCOM and dashed red line for the case without STATCOM) 

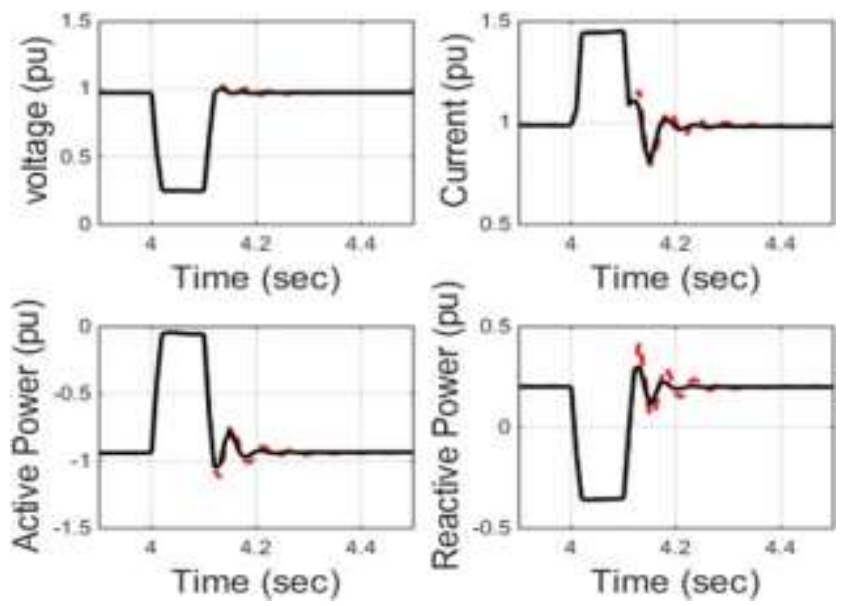

Figure 13: Dynamic performance of generator 2, Case 2; (solid black line for with STATCOM and dashed red line for the case without STATCOM)
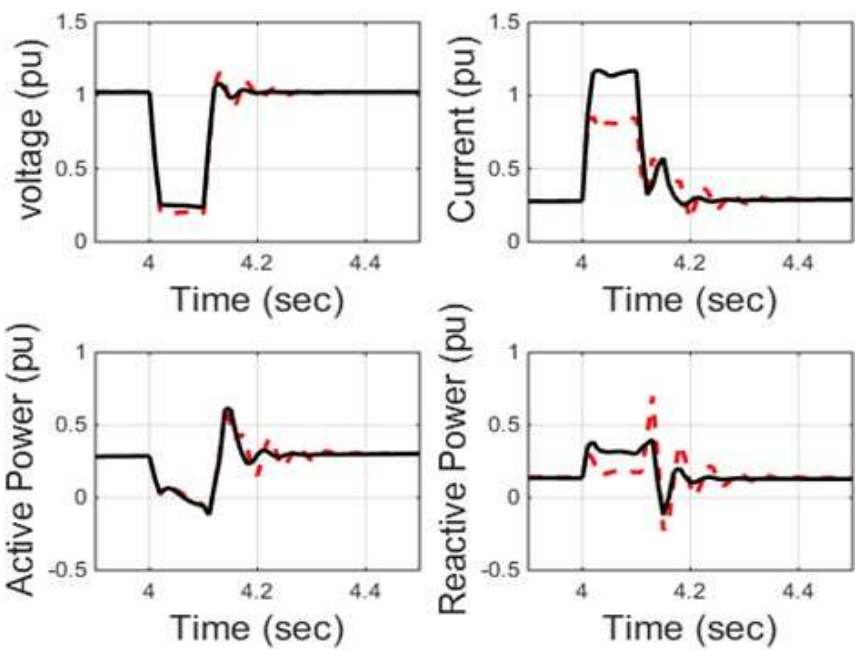

Figure 14: Dynamic performance of WF; (solid black line for with STATCOM and dashed red line for the case without STATCOM)
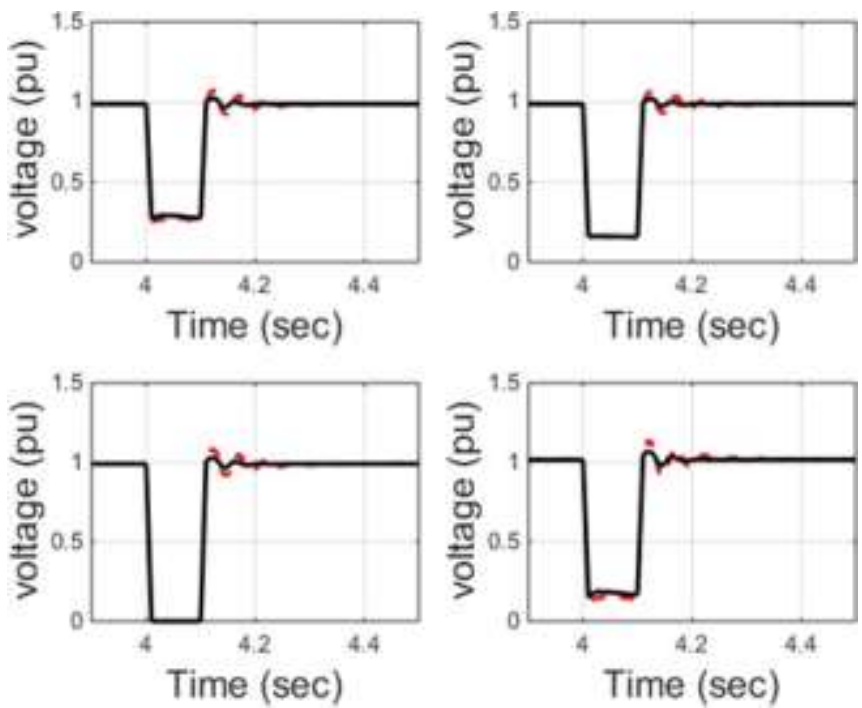

Figure 15: Dynamic performance of voltage at Buses B6, B7, B8, and B9, Case 2; (solid black line for with STATCOM and dashed red line for the case without STATCOM)

\subsection{Case 3: Fault located at Bus 9}

The last case of study in this paper, a three-phase fault has occurred at Bus 9. The fault is assumed to be occurred at 4 seconds and for duration of $0.1 \mathrm{sec}$. Figures 16, 17, 18 and 19 show the dynamic performance of the system under study under this case of study. The figures show that the system is stable and has a good dynamic performance with the proposed STATCOM based on the dynamic optimized PI-GA algorithm. Figure 16 shows the dynamic performance of the voltage, current, active and reactive power at generator 1. Moreover, Figures 17 and 18 show the dynamic performance at the generator 2 and WF bus 3 respectively. Furthermore, the time variation of the voltage at the reset busses has been shown in Figure 19. From the results, the system connected to STATCOM based on optimized dynamic PIGA has a good dynamic performance with respect to the settling time and the overshoot.
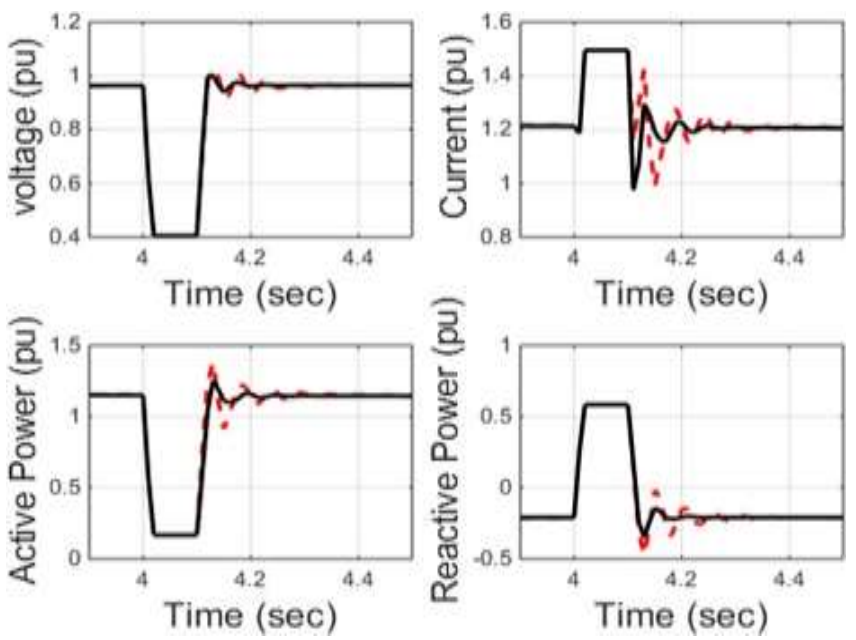

Figure 16: Dynamic performance of generator 1, Case 3; (solid black line for with STATCOM and dashed red line for the case without STATCOM)
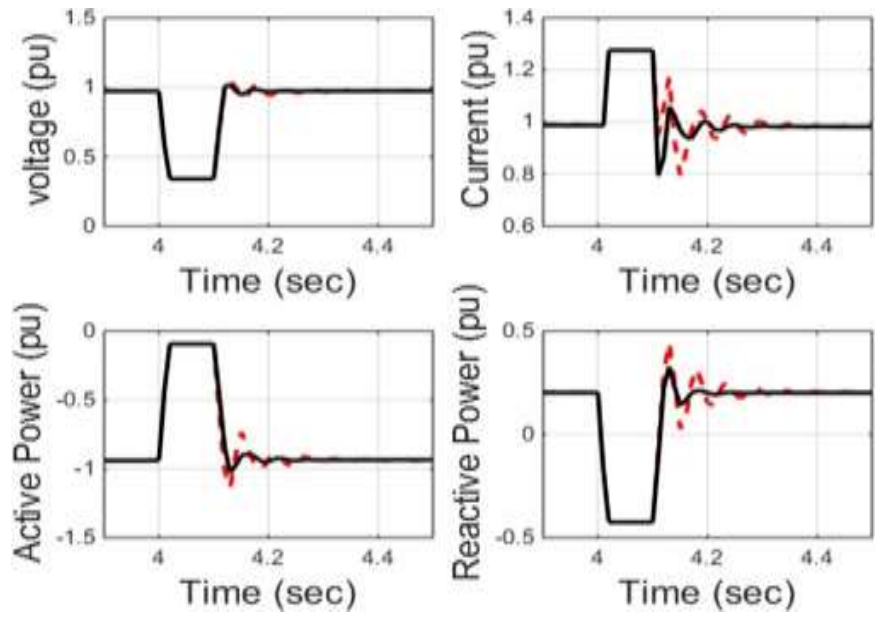

Figure 17: Dynamic performance of generator 2, Case 3; (solid black line for with STATCOM and dashed red line for the case without STATCOM) 

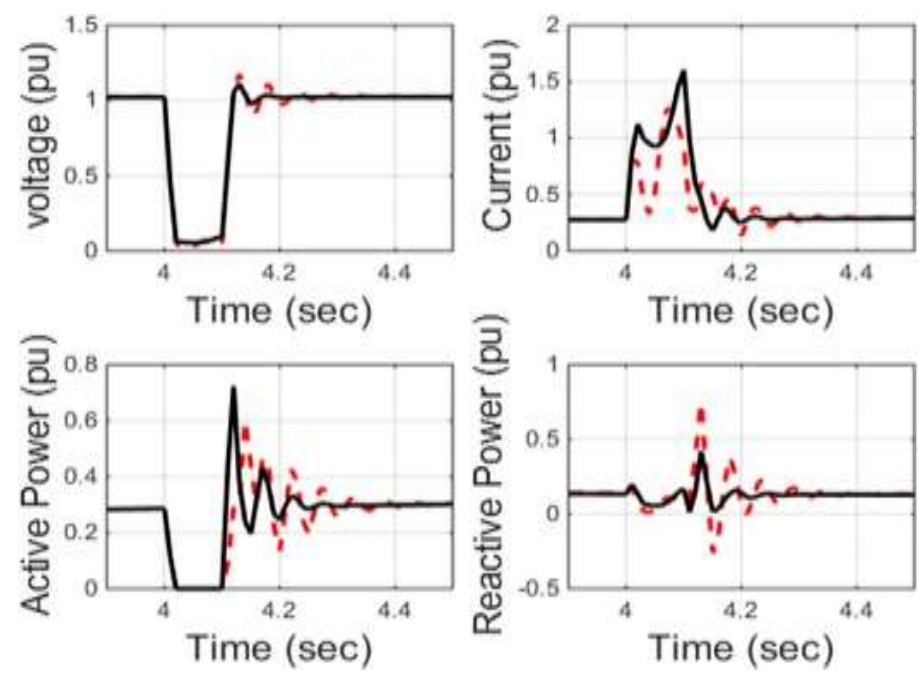

Figure 18: Dynamic performance of WF, Case 3; (solid black line for with STATCOM and dashed line for the case without STATCOM)
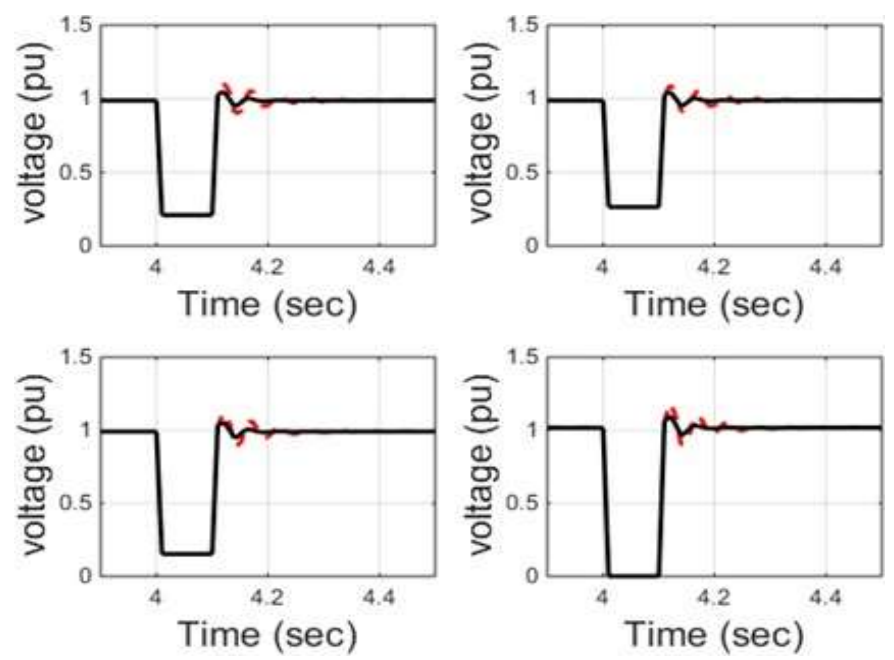

Figure 19: Dynamic performance of voltage at Buses B6, B7, B8, and B9, Case 3; (solid black line for with STATCOM and dashed red line for the case without STATCOM)

\section{Conclusion}

In this paper, the stability of the WSCC power system is analyzed with the presence of the wind power plant. Dynamic online optimized PI-GA controller has been used with STATCOM device for improving the system performance. Moreover, the controller is designed for online tuning the parameters of the PI controller using the GA optimization algorithm. The system is tested with three-phase faults at different locations. The dynamic performance of STAT- COM based on the dynamic optimized PI-GA and without STATCOM is compared and analyzed. The simulation results show that; the performance of the system under all cases of study with the STATCOM based the proposed online optimized PI-GA has a good settling time and acceptable overshoot. The proposed online optimized PI-GA has a better transient performance during the abnormal operating. Moreover, STATCOM based on the proposed optimized controller provides rapid recovery of terminal voltage after fault clearance. Furthermore, the integration of the STATCOM based proposed on the optimized dynamic PI-GA with wind turbine provides it better performance and stabilizes the system. For example, in the case of three-phase faults at the bus wind turbine, the system with the proposed STATCOM has a steady-state time of 0.1 second while the steady-state time is 0.15 second without Facts device.

\section{Conflict of Interest}

The authors declare no conflict of interest.

\section{References}

[1] B. Kusch, "Urban Renewable Energy on the Upswing: A Spotlight on Renewable Energy in Cities in REN21's "Renewables 2019 Global Status Report"," Resources, vol. 8, no. 3, p. 139, 2019/08/02, 2019,

doi: 10.3390/resources8030139.

[2] K. E. Okedu, "A Study of Wind Farm Stabilization Using DFIG or STATCOM Considering Grid Requirements," Journal of Engineering Science and Technology Review, vol. 3, no. 1, pp. 200-209, 2010.

doi: 10.25103/jestr.031.33.

[3] J. Olamaei, J. Javan, A. Yavartalab, and M. Khederzadeh, "Advanced Control of FACTS Devices for Improving Power Quality Regarding to Wind Farms," Energy Procedia, vol. 14, pp. 298-303, 2012,

doi: 10.1016/j.egypro.2011.12.933.

[4] A. A. Z. Diab and M. A. El-Sattar, "Adaptive model predictive based load frequency control in an interconnected power system," presented at the 2018 IEEE Conference of Russian Young Researchers in Electrical and Electronic Engineering (EIConRus), 2018/01, [Online]. Available:, 2018 http://dx.doi.org/10.1109/eiconrus.2018.8317170.

[5] M. A. Kamarposhti, M. Alinezhad, H. Lesani, and N. Talebi, "Comparison of SVC, STATCOM, TCSC, and UPFC controllers for Static Voltage Stability evaluated by continuation power flow method," presented at the 2008 IEEE Canada Electric Power Conference, 2008/10, 2008. [Online]. Available: http://dx.doi.org/10.1109/epc.2008.4763387.

[6] M. Laouer, A. Mekkaoui, and M. Younes, "STATCOM and Capacitor Banks in a Fixed-speed Wind Farm," Energy Procedia, vol. 50, pp. 882-892, 2014 ,

doi: 10.1016/j.egypro.2014.06.107.

[7] Y. Tang, H. He, Z. Ni, J. Wen, and X. Sui, "Reactive power control of gridconnected wind farm based on adaptive dynamic programming," Neurocomputing, vol. 125, pp. 125-133, 2014/02 2014,

doi: 10.1016/j.neucom.2012.07.046.

[8] A. A. Z. Diab, "Model Predictive Direct Power Control of Rotor Side Converter for DFIGs Driven by Variable Speed Wind Turbines," presented at the 2018 25th International Workshop on Electric Drives: Optimization in Control of Electric Drives (IWED), 2018/01, 2018. [Online]. Available: http://dx.doi.org/10.1109/iwed.2018.8321368.

[9] A. Ajami and M. Armaghan, "Application of Multi-Objective PSO Algorithm for Power System Stability Enhancement by Means of SSSC," International Journal of Computer and Electrical Engineering, pp. 838-845, 2010, doi: 10.7763/ijcee.2010.v2.237.

[10] M. J. Hossain, H. R. Pota, V. Ugrinovskii, and R. A. Ramos, "Robust STATCOM control for the enhancement of fault ride-through capability of fixed speed wind generators," presented at the 2009 IEEE International Conference on Control Applications, 2009/07, 2009.

[Online]. Available: http://dx.doi.org/10.1109/cca.2009.5281072.

[11] R. Kachroo and H. S. Dalvi, "Study of Various Types of Faults with Neuro Fuzzy Controlled SSSC and STATCOM in Stabilization of Grid Connected Wind Generator," presented at the 2012 Fifth International Conference on Emerging Trends in Engineering and Technology, 2012/11, 2012. 
[Online]. Available: http://dx.doi.org/10.1109/icetet.2012.57.

[12] C. D. Le and M. H. J. Bollen, "Ride-through of induction generator based wind park with switched capacitor, SVC, or STATCOM," presented at the IEEE PES General Meeting, 2010/07, 2010.

[Online]. Available: http://dx.doi.org/10.1109/pes.2010.5588109.

[13] H. Li, B. Zhao, C. Yang, H. W. Chen, and Z. Chen, "Analysis and estimation of transient stability for a grid-connected wind turbine with induction generator," Renewable Energy, vol. 36, no. 5, pp. 1469-1476, 2011/05 2011,

doi: 10.1016/j.renene.2010.08.023

[14] A. Moharana, R. K. Varma, and R. Seethapathy, "SSR Alleviation by STATCOM in Induction-Generator-Based Wind Farm Connected to Series Compensated Line," IEEE Transactions on Sustainable Energy, vol. 5, no. 3, pp. 947-957, 2014/07 2014, doi: $10.1109 /$ tste.2014.2311072.

[15] M. Molinas, S. Jon Are, and T. Undeland, "Low Voltage Ride Through of Wind Farms With Cage Generators: STATCOM Versus SVC," IEEE Transactions on Power Electronics, vol. 23, no. 3, pp. 1104-1117, 2008/05 2008 ,

doi: 10.1109/tpel.2008.921169.

[16] L. Qi, J. Langston, and M. Steurer, "Applying a STATCOM for stability improvement to an existing wind farm with fixed-speed induction generators," presented at the 2008 IEEE Power and Energy Society General Meeting - Conversion and Delivery of Electrical Energy in the 21st Century, 2008/07, 2008. [Online]. Available:

http://dx.doi.org/10.1109/pes.2008.4596894

[17] M. Stiebler, "PM synchronous generator with diode rectifier for wind systems using FACTS compensators," presented at the International Symposium on Power Electronics Power Electronics, Electrical Drives, Automation and Motion, 2012/06, 2012. [Online]. Available: http://dx.doi.org/10.1109/speedam.2012.6264410.

[18] G. Tian, S. Wang, and L. Guangchen, "Power quality and transient stability improvement of wind farm with fixed-speed induction generators using a STATCOM," presented at the 2010 International Conference on Power System Technology, 2010/10, 2010. [Online]. Available: http://dx.doi.org/10.1109/powercon.2010.5666419.

[19] Y. Xu and F. Li, "Adaptive PI Control of STATCOM for Voltage Regulation," IEEE Transactions on Power Delivery, vol. 29, no. 3, pp. 10021011, 2014/06, 2014,

doi: 10.1109/tpwrd.2013.2291576.

[20] A. R. Tavakoli, A. R. Seifi, and M. M. Arefi, "Designing a self-constructing fuzzy neural network controller for damping power system oscillations," Fuzzy Sets and Systems, vol. 356, pp. 63-76, 2019/02 2019, doi: 10.1016/j.fss.2018.01.006.

[21] A. Safari, A. Ahmadian, and M. A. A. Golkar, "Controller Design of STATCOM for Power System Stability Improvement Using Honey Bee Mating Optimization," Journal of Applied Research and Technology, vol. 11, no. 1, pp. 144-155, 2013/02, 2013, doi: 10.1016/s1665-6423(13)71523-2.

[22] V. Aparna, K. Mohamed Hussain, D. Najumnissa Jamal, and M. S. Murshitha Shajahan, "Implementation of Gain Scheduling Multiloop PI Controller Using Optimization Algorithms for a Dual Interacting Conical Tank Process," presented at the 2018 2nd International Conference on Trends in Electronics and Informatics (ICOEI), 2018/05, 2018.

[Online]. Available: http://dx.doi.org/10.1109/icoei.2018.8553895.

[23] M. M. Hato, S. Bouallegue, and M. Ayadi, "Water cycle algorithm-tuned PI control of a doubly fed induction generator for wind energy conversion," presented at the 2018 9th International Renewable Energy Congress (IREC), 2018/03, 2018

[Online]. Available: http://dx.doi.org/10.1109/irec.2018.8362516.

[24] O. Noureldeen, M. Rihan, and B. Hasanin, "Stability improvement of fixed speed induction generator wind farm using STATCOM during different fault locations and durations," Ain Shams Engineering Journal, vol. 2, no. 1, pp. 1-10, 2011/03, 2011, doi: 10.1016/j.asej.2011.04.002.

\section{Abbreviation and symbols}

\begin{tabular}{|l|l|}
\hline FACTS & Flexible AC Transmission Systems \\
\hline STATCOM & Static Synchronous Compensator \\
\hline GA & Genetic Algorithm \\
\hline PI & Proportional-Integral \\
\hline GA-PI & Genetic Algorithm -Proportional-Integral \\
\hline WES & Wind Energy System \\
\hline SVC & Static Var Compensator \\
\hline PID & Proportional Integral Derivative \\
\hline PSO & Particle Swarm Optimization \\
\hline HBMO & Honey Bee Mating Optimization \\
\hline SSSC & Static Synchronous Series Compensator \\
\hline DFIG & Doubly-Fed Induction Generator \\
\hline ISE & Integral Square Error \\
\hline t & Time \\
\hline dt & Time Derivative \\
\hline Qc & Reactive Power \\
\hline Xtr & Transformer Leakage Reactance \\
\hline UG & Utility Grid \\
\hline Vs & STATCOM output terminal voltage \\
\hline V1 & UG Voltage \\
\hline Iq & Reactive Current Component \\
\hline WSCC & Western Electricity Coordinating Council \\
\hline
\end{tabular}

